\title{
ENVIRONMENTAL CARE EXECUTION OPERATION OF GRB SYSTEM
}

\author{
Kazuo Wako \\ Kochi University of Technology, Kochi, Japan \\ Takehiko Iizuka \\ Giken Seisakusho Co. Ltd., Kochi, Japan
}

\begin{abstract}
In 1997, the semi-automatic unified system for piling work was developed and introduced to the market as the 'GRB SYSTEM'. This system is comprised of four distinct machines; the 'Silent Piler', the 'Unit Runner', the 'Clamp Crane', and the 'Pile Runner'. The 'Press-In' method, with its silent and vibration-free driving process, may be the solution to the widespread problem of noise and vibration on construction sites. Also the 'GRB SYSTEM' will bring, not only foundation work, but various other areas of construction into the new technologically-advanced era of construction work.
\end{abstract}

Keywords: GRB SYSTEM, Silent Piler, Clamp Crane, Unit Runner, Pile Runner, Press-In

\section{INTRODUCTION}

Accompanying the rapid development in robotics technology and machine automation, is an equally revolutionary change in design, function and capabilities of construction machinery. The technological driven change has resulted in the development of machines that are increasingly more power reliant and precise. Machinery is being designed to improve work safety, be more cost efficient, be less human dependent, and overall more precise. However, one area of construction that yet to benefit from technical wave of automation and efficiency, is foundation work, especially cofferdam work. Ironically, most public complaints to the construction industry concerning noise and vibration are due to foundation work. This field is still labor intensive and behind in robotics technology. The 'GRB SYSTEM' and the 'Silent Piler' will promote the automation of work, eliminate labor intensive job styles and the widespread problems of noise and vibration during foundation work.

\section{SOCIAL PROBLEMS}

The combination of urban expansion into areas once assessed as marginal and construction of increasingly higher buildings, has resulted in the need for both foundation and supporting piles to driven deeper into the stratum. This has resulted in an increase in noise and vibration pollution in urban areas. The Japanese Ministry of Environment has established seven types of environmental pollution: air pollution, water and earth contamination, bad odor, noise, vibration and ground subsidence.

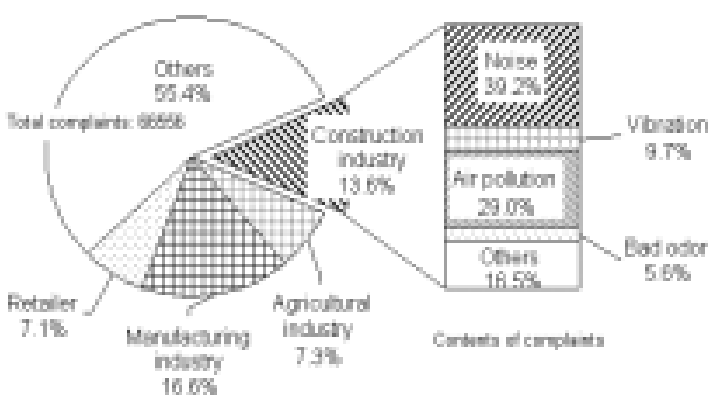

Figure 1 Public complaints to the industries

According to the 1996 Japanese
Environmental White Paper, noise pollution


comprised the largest number of complaints received. As Figure 1 shows, nearly $40 \%$ of public complaints to the construction industry were due to noise, while close to $10 \%$ were due to vibration problems. Cleary, the problem of noise and vibration at construction site is a serious management and environmental problem that must be taken into account during construction planning stage and execution stage.

\section{WHAT IS 'PRESS-IN'}

The idea of pressing a pile into the ground by static force is not a new idea, but it has taken time to develop a machine that is capable of consummating this idea. Generally, the concept of 'Press-In' is to covert the reaction force to the pressing force while operating free noise and vibration. If the reaction force is obtained by only the machine weight, the size of machine has to be massive. If it is brought by anchoring or a similar method, the working area must be expanded or other essential preparation work will be necessary. The 'Press-In' method can solve all these problems. From the 1970's through 1980's, press-in machines were developed in Japan and Europe in response to the environment towards eliminating the environmental problems of noise and vibration. To accomplish this, the machines used either their own weight, or the reaction force of the pre-installed piles. Giken Seisakusho, Japan, developed a machine which obtained a reaction force from pre-installed piles in 1975. This machine, the 'Silent Piler', is the one of the most innovative construction machines of 1970s due to its capability of performing noise and vibration free piling work. The principle of 'Press-In', realized by the 'Silent Piler', is the neutral equilibrium system between the ground (soil) and piles. Only if the press-in force exceeds the reaction force does the pile move downward until the system becomes stable again. The principle behind the press-in method is the balance between the alternative states of static and dynamic force. The static force is obtained from the pre-installed piles through clamps grabbing piles by hydraulic pressure. If there is no force from outside, the system is stable statically. Then additional pressure is added to the pile through the hydraulic press. Therefore, the pile moves silently down until the limit of static equilibrium or the end or the hydraulic presses stroke (see Figure 2). Thus, the press-in process is independent of the machine weight: It instead relies on the clamping capacity of the machine to maintain the pressure on the pile.

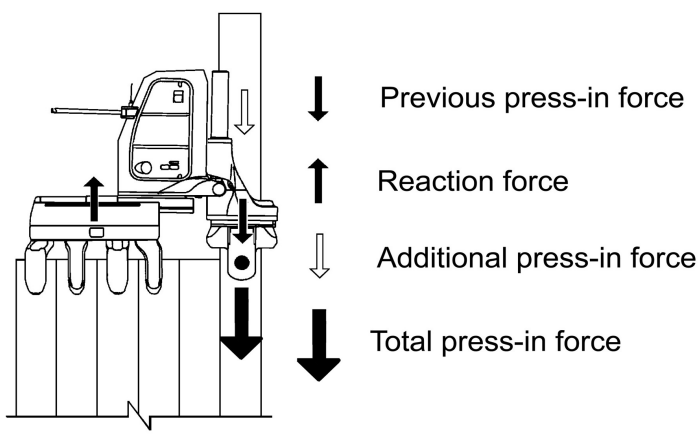

figure 2 Press-In mechanism

\section{GRB STSTEM}

In 1997, the semi-automatic unified system for piling work was developed and introduced to the market as the 'GRB SYSTEM'. This is comprised of four distinct machines: the 'Silent Piler', the 'Unit Runner', the 'Clamp Crane', and the 'Pile Runner'. The 'Silent Piler' is used for vibration free and ultra noise piling work. The 'Unit Runner' is a self-walking power unit. The 'Clamp Crane' feeds sheet piles or steel tubular piles to the 'Silent Piler'. The Pile Runner' is a semi-automatic material delivery machine for the 'Silent Piler'. The typical formation of 'GRB SYSTEM' is configured in a series on pre-installed piles. Each machine is operated either manually or semi-automatically. One operator can control the whole system or each unit individually, as the situation requires, using a radio-controller. The 'Silent Piler' is at the front of the 'GRB SYSTEM' following the 'Unit Runner' and the 'Clamp Crane'. The 'Pile Runner' moves back
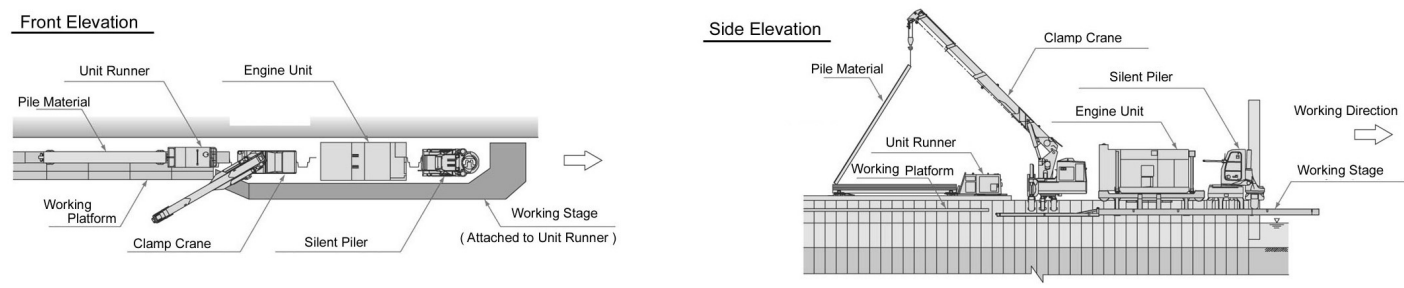

Figure 3 Formation of 'GRB SYSTEM' 
and forward between the material yard and work site, delivering piling materials. Piling material on the 'Pile Runner' is lifted by the 'Clamp Crane' and fed to the 'Silent Piler'. The 'Silent Piler' continues pressing piles in to the ground as long as sufficient materials are available or until the working limits of the 'Clamp Crane' are reached. While the 'Pile Runner' returns for more materials, the 'Unit Runner' and the 'Clamp Crane', under their own power, move forward to the next pile. Only one operator, using a semi-automated radio-controller, and a few workers are required to control this operation. The working capability of the 'GRB SYSTEM' is similar to the conventional vibro-driven technique, but without the problems of noise and vibration.

\section{SELF-WALKING FUNCTION}

\subsection{The 'Silent Piler'}

The 'Silent Piler' consists of three distinct parts linked together by a sliding rail and mast (Figure 4). The upper and lower parts of the machine slide horizontally on the rail of the lower body. The lower body has three or four clamping claws to hold the body on the piles by gripping the pre-installed piles tightly. The part attached to the upper body to grip the pile is referred to as a 'chuck'. It moves vertically up and down along with the mast of the upper body. This moving function allows for noise and vibration free static pile driving. Half-way through the pile press-in process, the clamping claws of the lower body release the piles (Figure 4:1). The body of the 'Silent Piler' is lifted up by the hydraulic press (Figure 4:2). The whole body is then held by the chuck and one pile. The lower body moves forward along the rail and sets on the piles.

\subsection{The 'Clamp Crane'}

The 'Clamp Crane's' basic mechanism of moving is almost similar to the 'Silent Piler' (Figure 5). The 'Clamp Crane' is composed of two parts: the Crane body and the clamping part. The first part of the crawling process is to open the first clamp (Figure 5:1). After that, the first clamp is lifted up and the crane body slides forward on the rail of the clamping frame. The first clamp is set and fixed tightly to the pile (Figure 3:2, 3:3). The second and third clamps are then opened and the crane body is lifted up by the hydraulic jack attached to the first clamp (Figure 5:4). Then, the second and third clamps slide together along the rail to the required position (Figure 5:5). Finally, the crane body is down using the hydraulic jack of the first clamp (Figure 5:6).

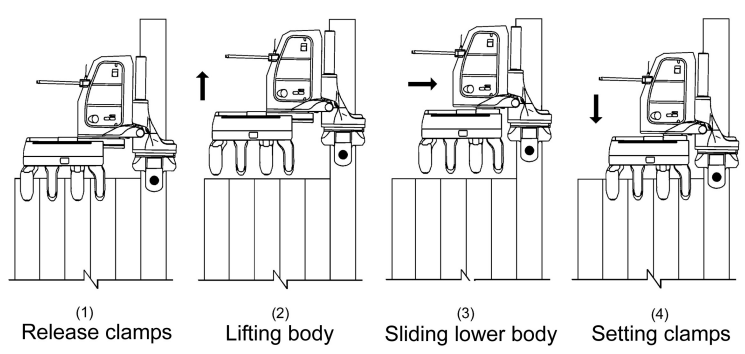

Figure 4 Self crawling on the piles
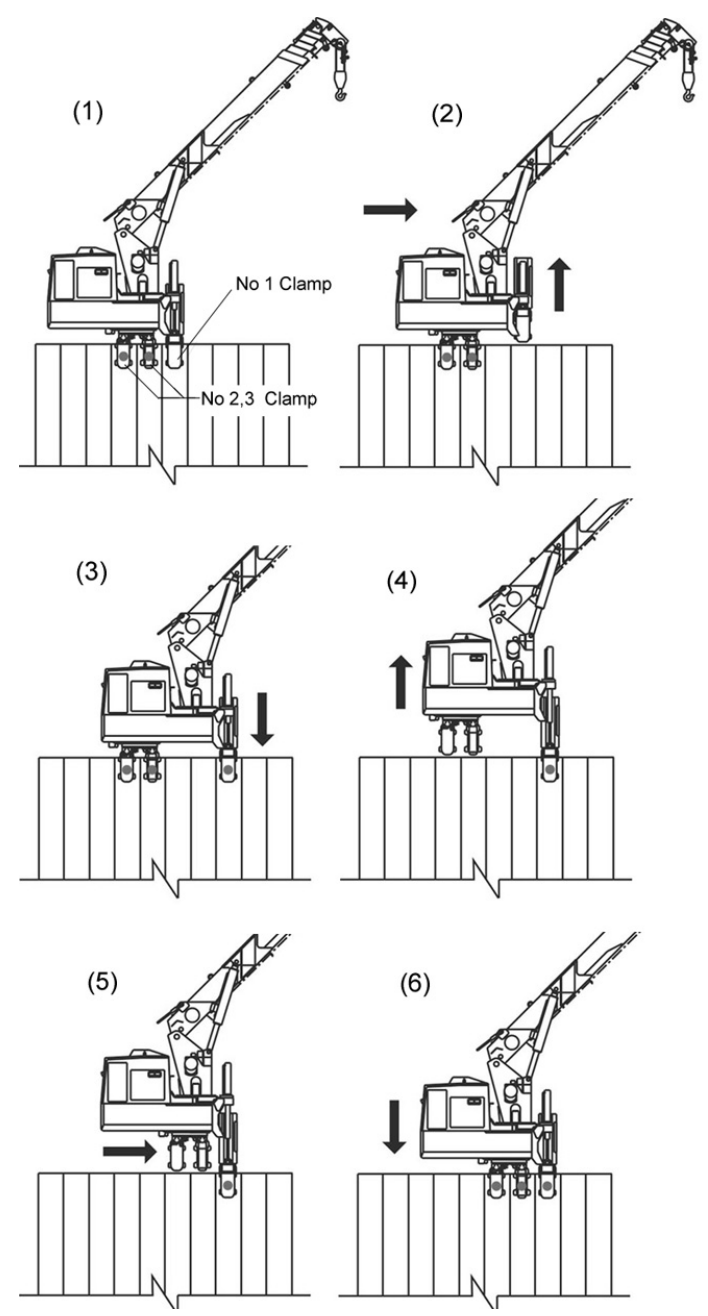

Figure 5 Self crawling mechanism of the 'Clamp Crane'

5.3 The 'Unit Runner' and The 'Pile Runner' 
Unlike the 'Silent Piler' and the 'Clamp Crane', the 'Unit Runner' and the 'Pile Runner' have no crawling mechanism. Both are driven by hydraulic motor driven wheel, either on the pre-installed piles or on the sheet pile railway set on the pre-installed piles. The 'Unit Runner' is the carrier base of the engine unit and its bladed roller catches the gaps and uneven pile surfaces (Figure 6). It is also equipped with guide roller to prevent falling and keep machine posture stable. The rollers are held to the pile wall by the constant pressure applied by the hydraulic accumulator. Each of the rollers in the guide unit has the ability to adjust to a curved line while maintaining the stability of the 'Unit Runner'

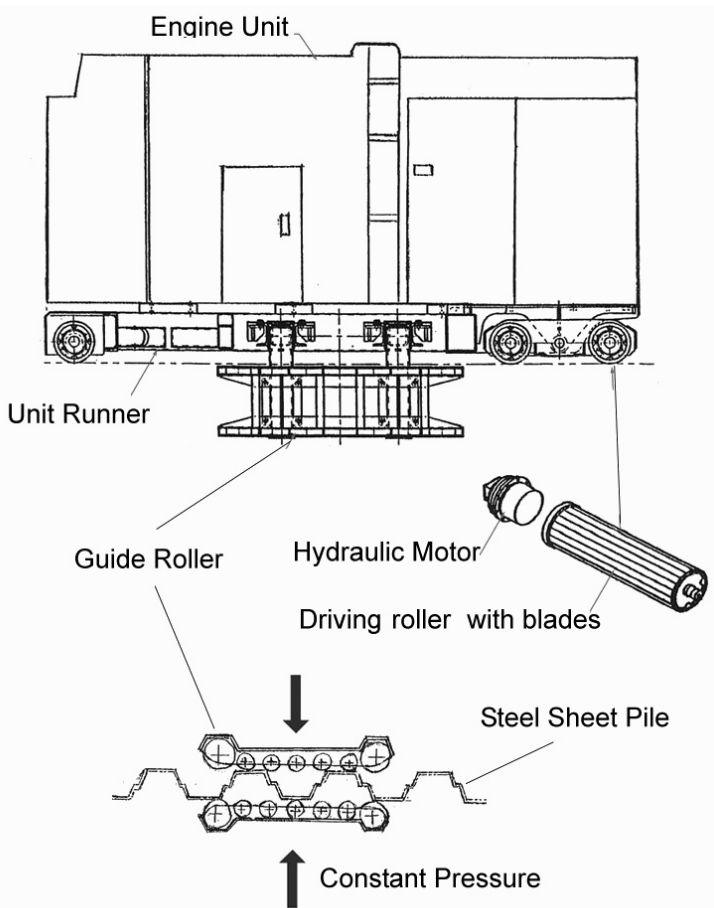

Figure 6 The wheel drive mechanism of the 'Unit Runner' and guide roller

\section{CLAMP MECHANISM}

As described in the 'Press-In' method, the static pile press requires a reaction force from the pre-installed piles. To realize a high reaction force, or in other word, a high pressing power, the clamping capability of this machine is an important and key technology. Unlike other pile-pressing machine, the pile-pressing force of the 'Silent Piler' is not created by its weight but through a reaction force from the pre-installed piles. To transfer the reaction force effectively from the pre-installed piles to the press-in function [the chuck], there must be an efficient and strong clamping capacity. The ultra high-pressure hydraulic pump is attached to this machine. The pump has a rating of $68.8 \mathrm{Mpa}(700 \mathrm{~kg} / \mathrm{cm} 2)$ with a maximum flow rate of 800 liters per minute. Even now, this pump still has double the capacity of other newer hydraulic excavation machines [34.3Mpa see Figure 7]. Because of the different types of piles, a variety of clamps are essential to hold the various pile shapes. Figures 9 and 10 show these clamping methods.

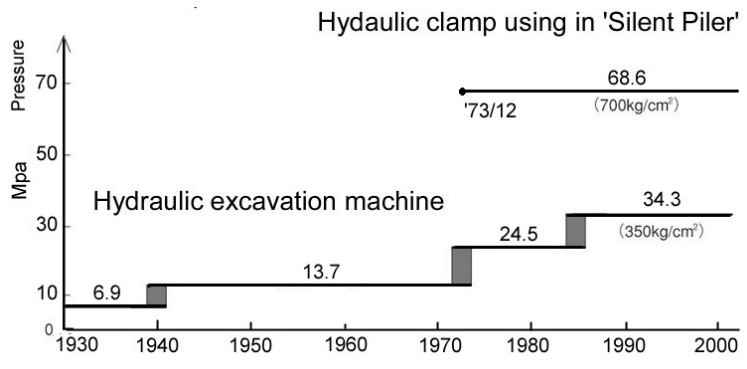

Figure 7 Comparison of hydraulic pressure

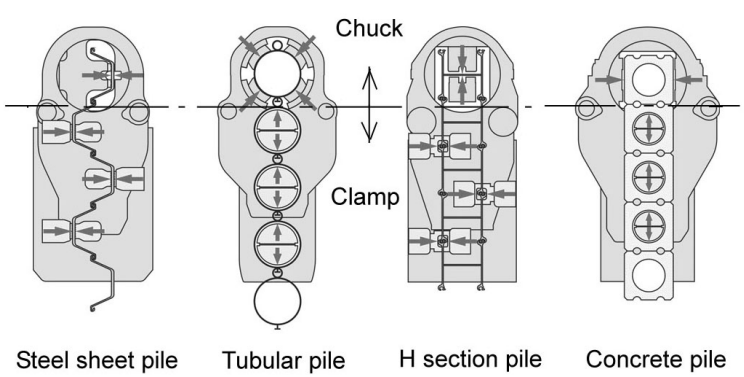

Figure 8 Various type of clamp

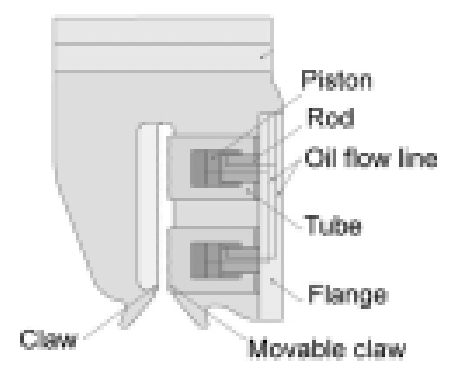

Figure 9 Cross section of clamp 


\section{APPLICATIONS}

After the introduction of the 'Silent Piler' and 'GRB SYSTEM', the befits of both systems soon become apparent. The most significant features are ultra low noise and vibration free operation for piling work in marginal areas. For example, besides buildings (see Figure 10); underneath bridges due to their compact size (see Figure 11). Also, the system eliminates the need for temporary scaffolding and staging work, therefore, reducing the workforce and permitting stand-alone operation (see Figure 12).

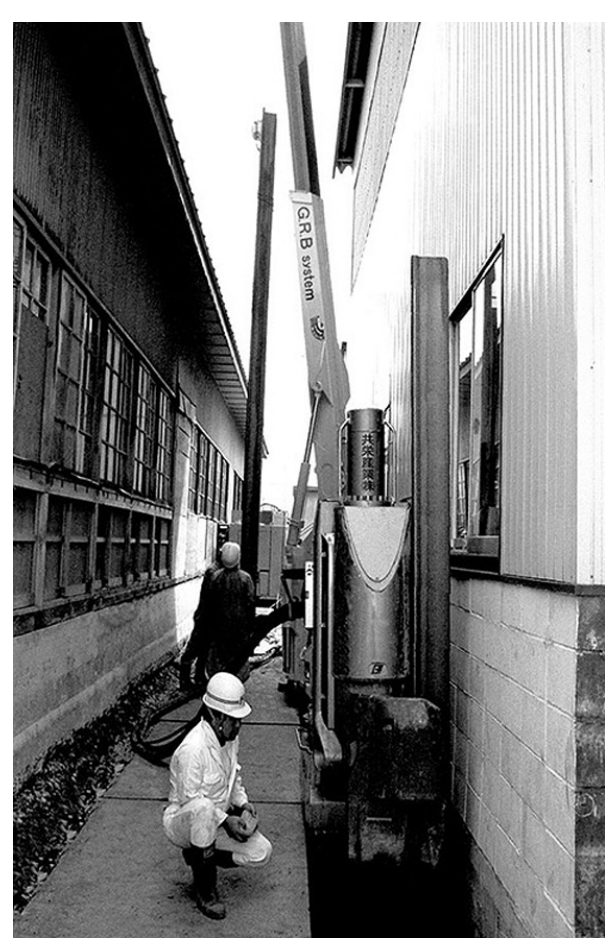

Figure 10 Piling work at the marginal area

\section{POTENTIALITY OF 'PRESS-IN'}

Although the 'Press-In' method is still undergoing research and development, its application is widespread. For example, the retrofit reinforcement of buildings and embankments. Also, experimentally in Japan, single steel tubular piles for bridge piling foundations were pressed into the solid stratum and single $\mathrm{H}$ section steel piles were applied to the open caisson construction as pressing piles as in circular shape. This unique evolutionary system will bring not only foundation work but various areas of construction into the new technologically-advanced era of construction work.

There are many significant benefits the 'Press-in' method and 'GRB SYSTEM' can bring to construction sites. First, the 'Press-in' method will eliminate the social problems of noise and vibration which, currently, are considered the inevitable by-product of construction work in urban areas. Second, the 'GRB SYSTEM' will allow the potential development of marginal areas which have been developed due to the narrow space and zero tolerance of noise and vibration by members of public. Third, it will drastically reduce unessential work such as temporary scaffolding and construction of access roads for materials to be delivered. Consequently, the total cost and completion time of the project will greatly reduced. Fourth, the essential work force will be reduced markedly due to the semi-automated unified system. As a result of this, the possibility of labor accidents will possibly decrease. Finally, the working environment will dramatically improve and the current image of construction site work as dirty, dangerous and tough will be transformed to a more

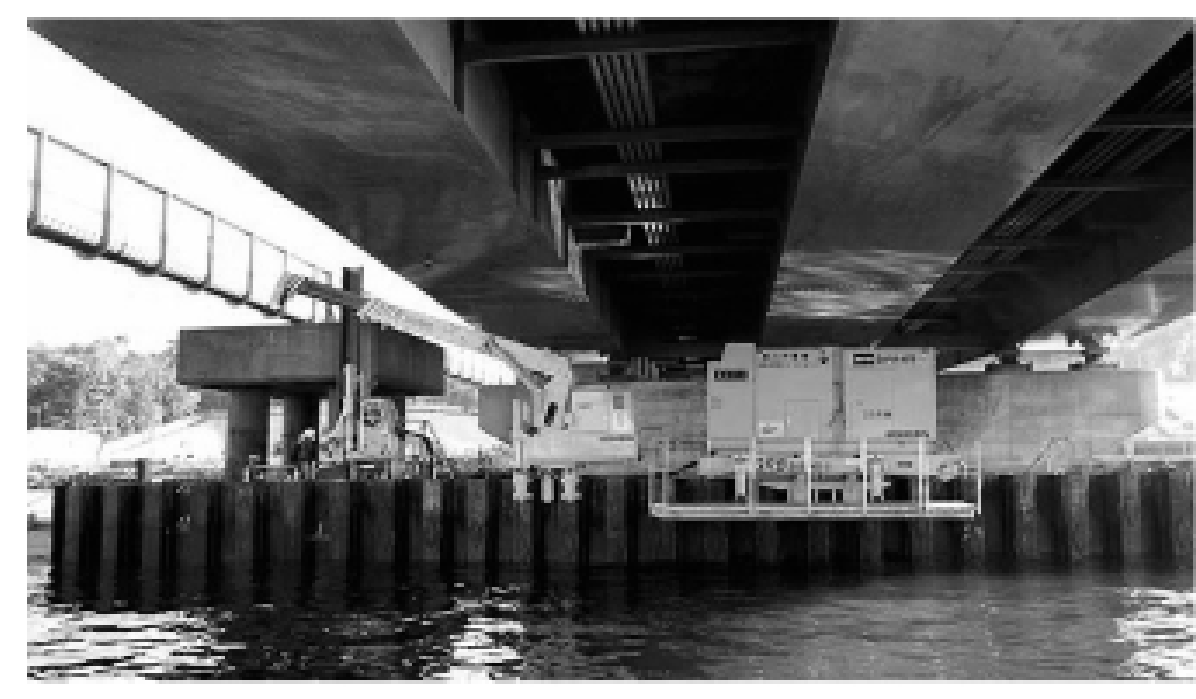

Figure 11

Piling work under the bridge 


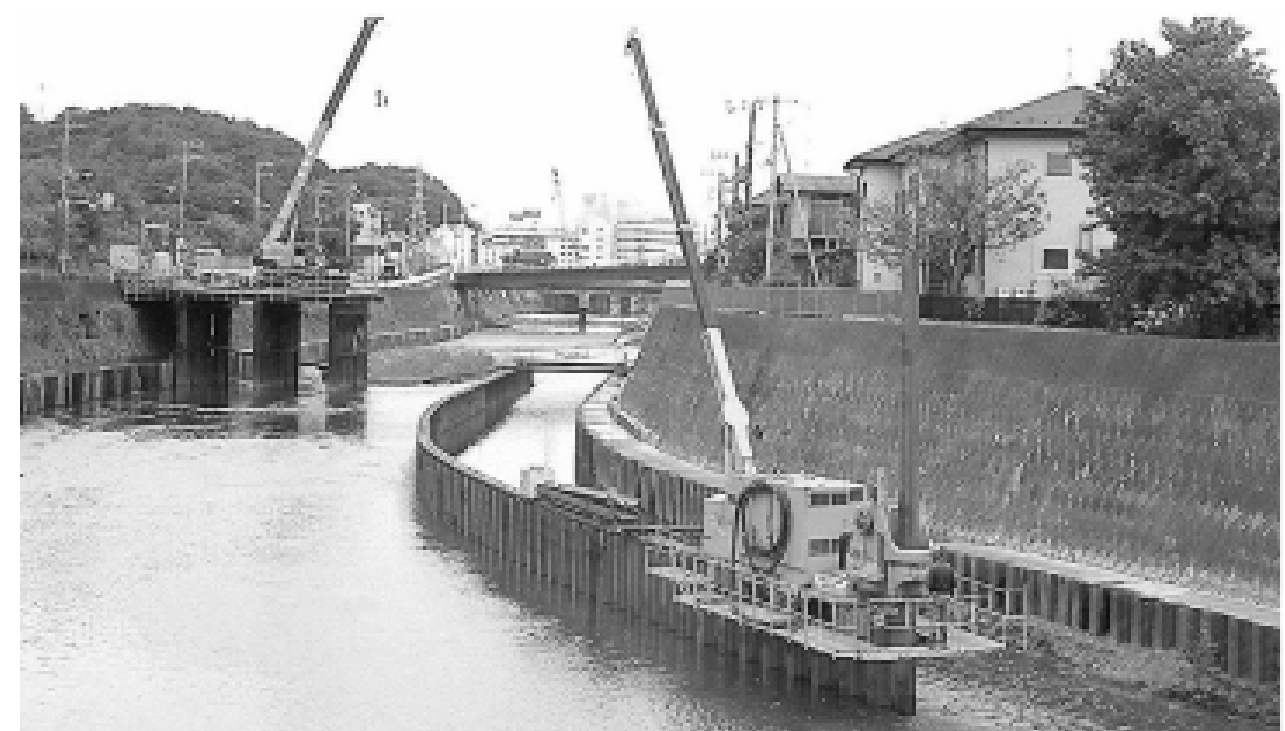

Figure 12

Piling work

along the river

appealing one.

1996.

\section{CONCLUSION}

'Press-In' technology has the potential to diminish or even eliminate the problems of noise and vibration due to its simple procedure and mechanism. With the absence of noise and vibration during foundation work, a major source of concern for construction management is removed. With the removal of noise and vibration, the need for excessive noise protection measures and measuring and controlling staff will no longer be necessary. In addition, the possibility of suspension of work due to noise or vibration will be removed as a concern of management. The resources used to deal with these problems can now be utilizes in other more works and purposes. Although it can be argued that foundation work is only one small part of a construction project, it must be remembered that it accounts for a significant percentage of all complaints received. With the adoption of 'Press-In' technology, not only are the concerns of public being met but also a constant source of problems for management is removed.

\section{REFERENCES}

[1] Ministry of Environment., Environmental White Paper, Ministry of Environment, Japan., 1996.

[2] Ministry of Environment., Pollution Arbitration

White Paper, Ministry of Environment, Japan.,
[3] Ministry of Construction., Construction White Paper, Ministry of Construction, Japan., 1999.

[4] TESPA, INSTALLATION OF STEEL SHEET PILES, Technical European Sheet Piling Association, 1993. 